\title{
Estudo químico, macroscópico e da resistência à flexão de placas e parafusos de titânio usados na fixação interna rígida ${ }^{\dagger}$
}

\section{Chemical, macroscopical and bending resistance study of titanium plates and screws used in internal rigid fixation}

\author{
Alexandre Elias TRIVELLATO* \\ Renato MAZZONETTO** \\ Luis Augusto PASSERI*** \\ Simonides CONSANI***
}
TRIVELLATO, A. E.; MAZZONETTO, R.; PASSERI, L. A.; CONSANI, S. Estudo químico, macroscópico e da resistência à flexão de placas e parafusos de titânio usados na fixação interna rígida. Pesqui Odontol Bras, v. 14, n. 4, p. 392-398, out./dez. 2000.

\begin{abstract}
O objetivo deste estudo foi comparar quatro sistemas de placas e parafusos de titânio de 2,0 mm de diâmetro utilizados em fixação interna rígida, sendo duas marcas nacionais (Engimplan e Bucomax) e duas importadas (Synthes e W. Lorenz). Foram realizadas as seguintes análises: composição química, através de espectrometria por dispersão de energia (EDS) e espectrometria de emissão atômica (AES), macroscópica, por meio de medidas padronizadas e de resistência à flexão. Os resultados obtidos permitem concluir que as marcas nacionais apresentaram um comportamento inferior, em relação a padronização das dimensões das placas e parafusos avaliados, influenciando nos resultados dos testes de flexão, para os quais estas se comportaram da mesma maneira. Entretanto, a marca comercial W. Lorenz utiliza liga de titânio-6aluminio-4vanádio para a confecção dos parafusos, fato responsável pelo melhor resultado no teste de flexão que qualquer outra marca. Os demais parafusos e placas apresentaram-se constituídos de titânio comercialmente puro, de acordo com a EDS e posteriormente confirmados pela AES.
\end{abstract}

UNITERMOS: Placa; Parafuso; Análise química; Resistência à flexão.

\section{INTRODUÇÃO}

O termo fixação interna é utilizado para designar a estabilização de uma fratura ou osteotomia, com dispositivo em contato direto com a estrutura óssea, podendo ser obtida por meio de fio de aço, parafuso ou associação de placa e parafuso. É designada rígida quando o dispositivo de imobilização junto à estrutura óssea permite a função do órgão durante o processo de reparação óssea. Caso não seja possivel o restabelecimento da função ou necessite de outras forma de fixação, é denominada não rígida ${ }^{4}$. A fixação promovida por parafusos ou associação de placas e parafusos é a que apresenta melhores resultados ${ }^{9}$. Atualmente, existem no mercado várias marcas comerciais de placas e parafusos, algumas de alta qualidade e outras manufaturadas quase que artesanalmente. Por essa razão, estudos a respeito da qualidade desses dis- positivos são necessários, com o objetivo de avaliar o seu comportamento.

\section{MATERIAIS E MÉTODOS}

No presente estudo, foram utilizadas quarenta placas e quarenta parafusos, do sistema $2,0 \mathrm{~mm}$, das seguintes marcas comerciais: Engimplan (Engenharia de Implantes Ind. Com. Ltda., Rio Claro, São Paulo, Brasil), Bucomax (G. M. Reis Jr. Ind. Com. Imp. Exp., Campinas, São Paulo, Brasil), Synthes (Synthes Indústria e Comércio Ltda., Suiça) e W. Lorenz (Walter Lorenz, Alemanha), observados na Figura 1.

As placas em estudo tinham indicação para terço médio da face, apresentando conformação reta e de quatro furos, exceto as da marca Synthes, adquiridas com 20 furos e seccionadas posteriormente. Já os parafusos possuíam 2,0 mm de diâ-

$\dagger$ Dissertação de Mestrado.

* Aluno do Curso de Pós-Graduação na Área de Cirurgia Buco-Maxilo-Facial; ** Professores Assistentes Doutores da Área de Cirurgia Buco-Maxilo-Facial; *** Professor Titular da Área de Materiais Dentários - Faculdade de Odontologia de Piracicaba da UNICAMP. 
TRIVELLATO, A. E.; MAZZONETTO, R.; PASSERI, L. A.; CONSANI, S. Estudo químico, macroscópico e da resistência à flexão de placas e parafusos de titânio usados na fixação interna rígida. Pesqui Odontol Bras, v. 14, n. 4, p. 392-398, out./dez. 2000.

metro externo de rosca e $12 \mathrm{~mm}$ de comprimento, exceto os da marca W. Lorenz que possuíam $11 \mathrm{~mm}$ de comprimento.

\section{Análise química}

\section{Espectrometria por dispersão de energia (EDS)}

Para proceder-se esta análise, foi realizada a inclusão em resina acrílica quimicamente polimerizável de uma placa e um parafuso de cada sistema conforme aquisição comercial, totalizando 8 corpos-de-prova.

As superficies das placas e parafusos foram submetidas ao polimento mecânico com lixas d'água de granulação de 200 a 1.200 , seguido de polimento com feltro embebido em solução aquosa de alumina com granulação $0,3 \mu \mathrm{m}$, em politriz elétrica. Posteriormente, as superficies polidas foram submetidas ao ataque químico, por 30 segundos, com reagente de Kroll, (3 $\mathrm{ml}$ de ácido fluorídri-

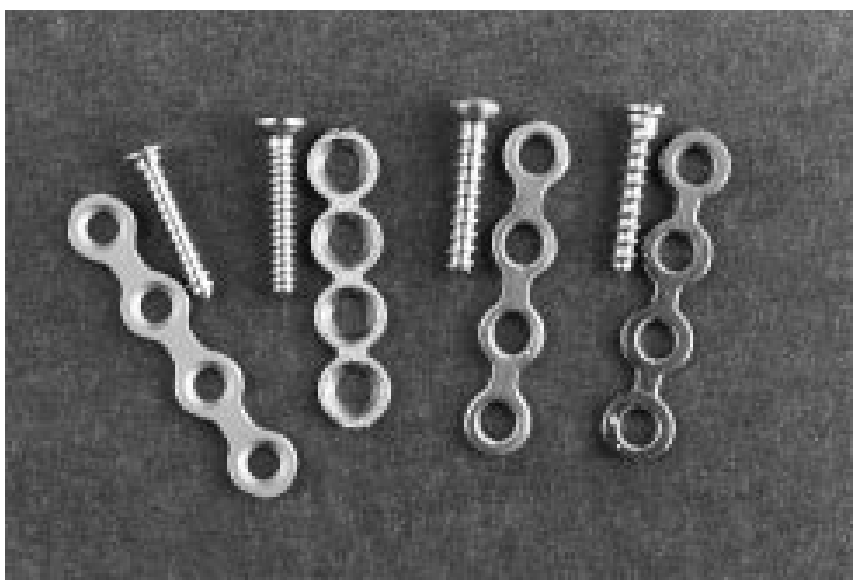

FIGURA 1 - Placa e parafuso dos sistemas avaliados. Da esquerda para direita: W. Lorenz, Synthes, Bucomax e Engimplan. co e $6 \mathrm{ml}$ de ácido nítrico, diluídos em $1.000 \mathrm{ml}$ de água destilada). Imediatamente após o ataque químico, procedia-se à remoção das placas e parafusos da resina acrílica e iniciava-se a análise em microscópio eletrônico de varredura JEOL-JSM, modelo T-330 A (Alemanha).

\section{Espectrometria de emissão atômica (AES)}

Duas placas e dois parafusos de cada marca comercial foram submetidos à análise química para determinação dos elementos aluminio, ferro e vanádio, fornecendo subsídios para a classificação em titânio comercialmente puro e liga de titânio-alumínio-vanádio. A análise foi realizada por meio de espectrometria de emissão atômica (AES), num espectrômetro de emissão atômica (Atom Scan 25 - Thermo Jarrel Ash, EUA).

\section{Análise macroscópica}

Foram realizadas mensurações com paquímetro digital (Mitutoyo, modelo CD-6"BS), em dez placas e dez parafusos de cada marca comercial. Nas placas, foram realizadas mensurações em seis medidas e nos parafusos em quatro, conforme esquema da Figura 2. Para cada medida, foram realizadas três mensurações, sendo posteriormente estabelecida a média final.

\section{Testes de flexão}

\section{Placas}

Sete placas de cada marca comercial foram submetidas ao teste. Cada placa foi incluída em resina acrílica quimicamente polimerizável, contida em cilindro de PVC, com 12,5 mm de diâmetro interno por $20,0 \mathrm{~mm}$ de comprimento, de modo a deixar dois furos expostos. No último furo exposto da placa foi adaptado fio ortodôntico em forma de alça, medindo $100 \mathrm{~mm}$ de comprimento e $0,5 \mathrm{~mm}$

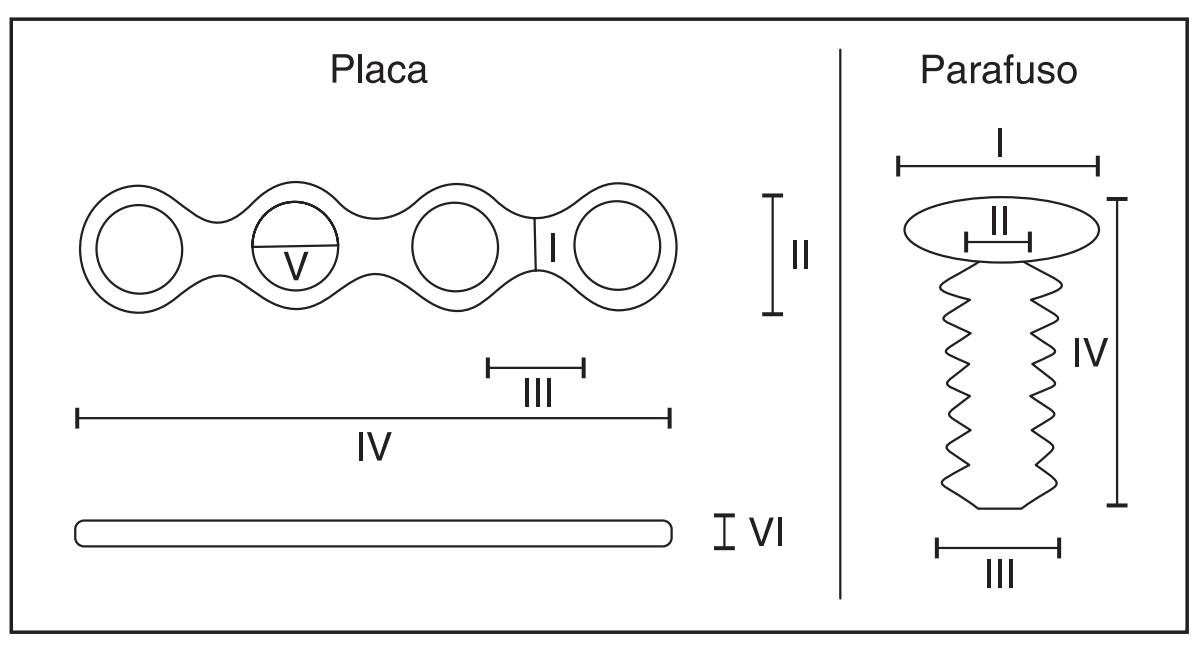

FIGURA 2 - Esquema ilustrativo dos locais de realização das medidas. 
TRIVELLATO, A. E.; MAZZONETTO, R.; PASSERI, L. A.; CONSANI, S. Estudo químico, macroscópico e da resistência à flexão de placas e parafusos de titânio usados na fixação interna rígida. Pesqui Odontol Bras, v. 14, n. 4, p. 392-398, out./dez. 2000.

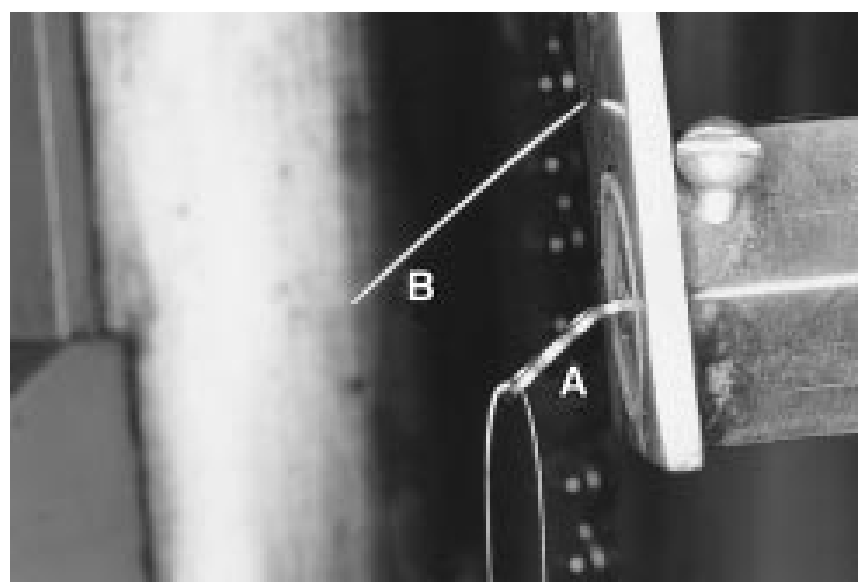

FIGURA 3 - Disposição da placa no final do teste de flexão (A); paralelismo ao referencial de $45^{\circ}$ (B).

de diâmetro. O cilindro de resina contendo a placa foi adaptado numa luva metálica fixada no mordente superior da máquina de ensaio. No mordente inferior, foi fixada a extremidade da alça do fio ortodôntico. Para orientação da amplitude de flexão, foi adaptado na luva metálica um fio de aço inoxidável, numa angulação de $45^{\circ} \mathrm{em}$ relação à luva. Esse dispositivo serviu de referencial para a interrupção da força exercida sobre a placa, isto é, quando a dobradura da placa estabelecia paralelismo com o fio (Figura 3). No presente teste, foi utilizada máquina de ensaio universal Otto Wolpert-Werke (Alemanha), calibrada numa velocidade de $6 \mathrm{~mm} / \mathrm{min}$, com escala de carga de $0-20 \mathrm{~kg}$.

\section{Parafusos}

Da mesma maneira que as placas, sete parafusos de cada marca comercial foram submetidos ao teste de resistência à flexão. Foi confeccionado um dispositivo de aço, para a fixação dos parafusos, composto de duas partes, fixadas com quatro parafusos para mantê-las unidas durante a realização do teste. $\mathrm{Na}$ área central de ambas, foi feita uma ranhura de $0,5 \mathrm{~mm}$ de profundidade, para melhor adaptação do parafuso. A extremidade da cabeça do parafuso ficava $2 \mathrm{~mm}$ além da margem do dispositivo de fixação, e a ponta ativa responsável pela flexão do parafuso, movia-se a velocidade de $6 \mathrm{~mm} / \mathrm{min}$, numa escala de carga de $0-200 \mathrm{~kg}$. A flexão era permitida até a dobradura do parafuso atingir $45^{\circ}$, conforme indicação de um fio de aço colocado a $45^{\circ}$ no dispositivo que fixava o parafuso (Figura 4). Esse teste foi efetuado numa máquina de ensaio universal Losenhausenwerk (Alemanha).

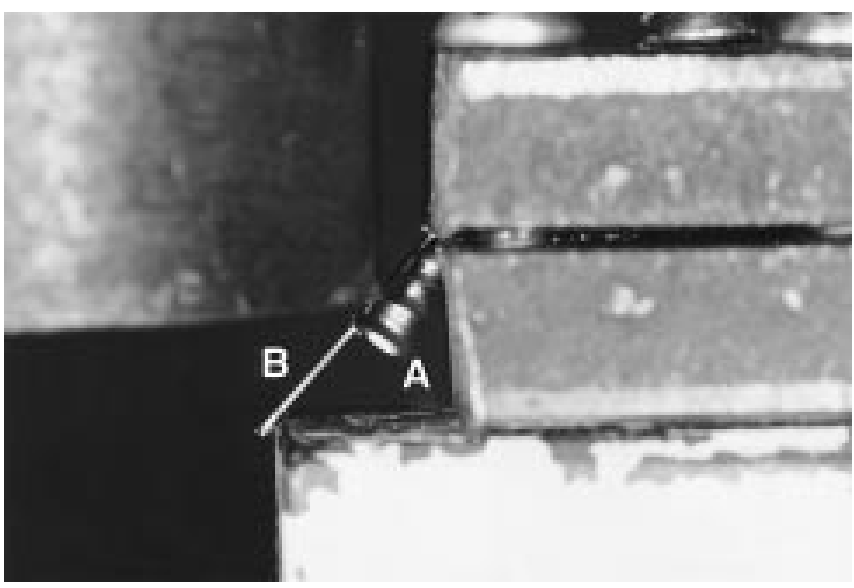

FIGURA 4 - Disposição do parafuso no final do teste de flexão (A); paralelismo ao referencial de $45^{\circ}$ (B).

\section{RESULTADOS}

\section{Análise química}

\section{Espectrometria por dispersão de energia (EDS)}

A espectrometria por dispersão de energia (EDS) realizada nas placas e parafusos apresentou resultados semelhantes para as marcas comerciais Engimplan, Bucomax, Synthes e para a placa W. Lorenz, evidenciando titânio comercialmente puro. Com relação ao parafuso da marca W. Lorenz, o resultado foi compativel com liga de titânio-alumínio-vanádio. As representações gráficas destas análises estão nos Gráficos 1 e 2, onde os elementos são simbolizados pelos picos presentes.

\section{Espectrometria de emissão atômica (AES)}

O resultado obtido pela análise química é mostrado na Tabela 1.

De acordo com os valores mostrados na Tabela 1 , é possivel afirmar que o parafuso da marca comercial W. Lorenz é constituído de liga de titânio (titânio-6alumínio-4vanádio), segundo normas da ASTM F $1108-97^{2}$ e da ISO/DIS 5832-3: $1993^{8}$. Os demais materiais avaliados constituem-se de titânio comercialmente puro, segundo normas da ASTM F 67-95 e da ISO/DIS 5832-2: 19937 . Ainda, com base nas normas para o titânio comercialmente puro e tendo-se o elemento ferro como critério de avaliação, é admitido que a placa da marca comercial W. Lorenz é composta de titânio comercialmente puro grau 2, segundo a norma ISO/DIS 5832-2: 19937 , e grau 1, segundo norma ASTM F $67-95^{1}$. Os demais materiais avaliados são classificados como grau 1, nas duas normas citadas. 
TRIVELLATO, A. E.; MAZZONETTO, R.; PASSERI, L. A.; CONSANI, S. Estudo químico, macroscópico e da resistência à flexão de placas e parafusos de titânio usados na fixação interna rígida. Pesqui Odontol Bras, v. 14, n. 4, p. 392-398, out./dez. 2000.

\section{Análise macroscópica}

A média final e o desvio-padrão obtidos em cada medida estipulada nas placas e nos parafusos, das quatro marcas comerciais, são apresentados respectivamente nas Tabelas 2 e 3 .

\section{Testes de flexão}

Aplicando-se o teste de Tukey, ao nível de significância de $1 \%$, para os valores obtidos durante os testes de flexão das placas e dos parafusos, verifica-se que no caso das placas houve diferença estatisticamente significante entre as marcas comerciais importadas e nacionais, com vantagem para as importadas, mas não entre as duas importadas e as duas nacionais. Já com relação aos parafusos, houve diferença estatisticamente significante entre as marcas comerciais importadas e nacionais, com vantagem para as importadas, assim como ocorreu diferença entre as importadas com vantagem para W. Lorenz, sendo que as nacionais não apresentaram diferença significante (Tabelas 4 e 5).

\section{DISCUSSÃO}

Pela espectrometria por dispersão de energia (EDS), foi possivel ter uma noção qualitativa dos elementos químicos presentes e constatou-se que o parafuso da marca comercial W. Lorenz é constituído de liga de titânio-alumínio-vanádio e os demais materiais são de titânio comercialmente puro.

Por meio da análise da composição química realizada pela espectrometria de emissão de plasma induzido, pôde-se constatar a presença do titânio comercialmente puro em todas as placas avaliadas. Entretanto, a placa da W. Lorenz foi classificada como grau 2, de acordo com a norma
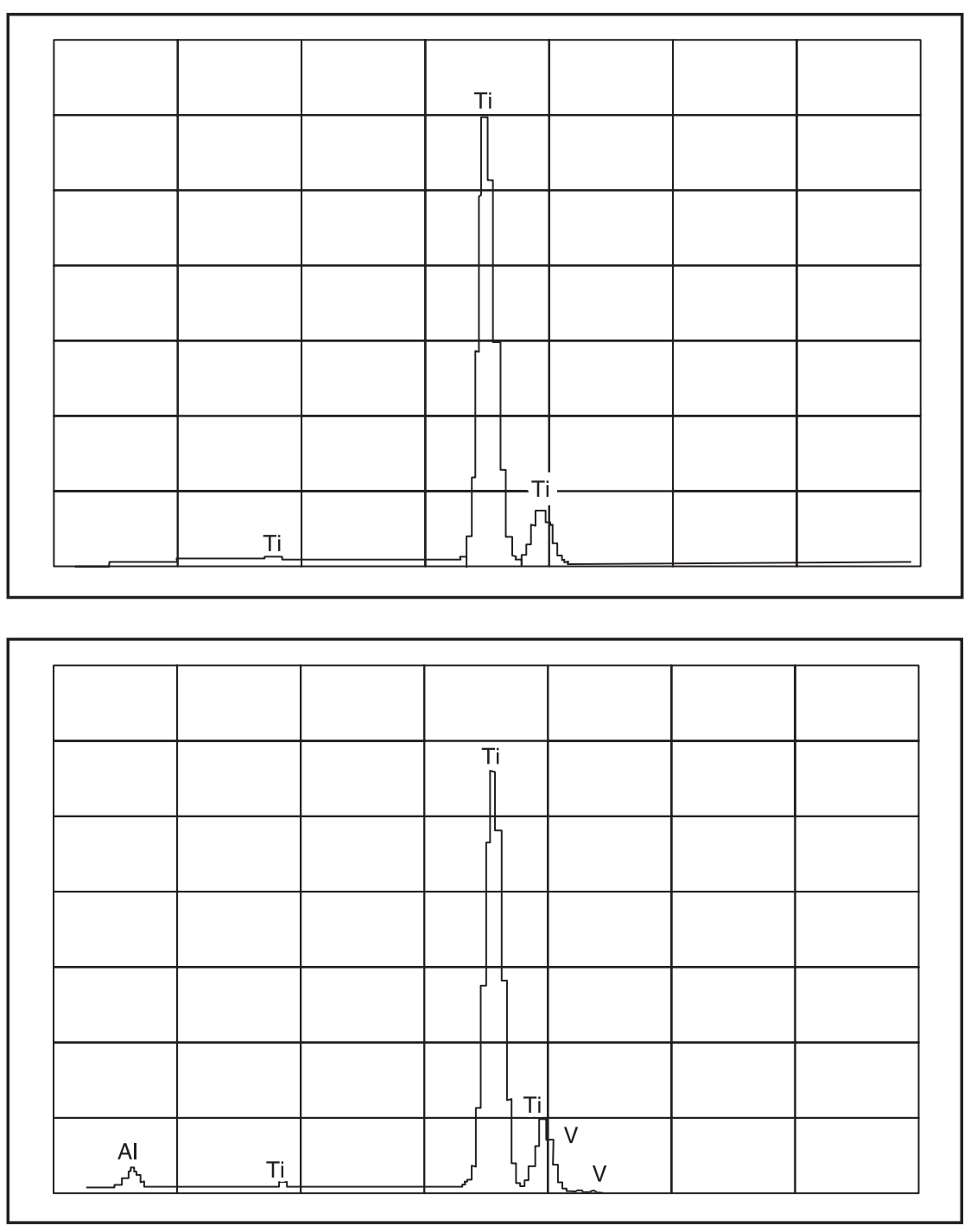

GRÁFICO 1 - Espectrometria por dispersão de energia para o titânio comercialmente puro. O eixo vertical representa a energia liberada e o horizontal o comprimento de onda.
GRÁFICO 2 - Espectrometria por dispersão de energia para a liga de titânio-aluminio-vanádio. $\mathrm{O}$ eixo vertical representa a energia liberada e o horizontal o comprimento de onda. 
TRIVELLATO, A. E.; MAZZONETTO, R.; PASSERI, L. A.; CONSANI, S. Estudo químico, macroscópico e da resistência à flexão de placas e parafusos de titânio usados na fixação interna rígida. Pesqui Odontol Bras, v. 14, n. 4, p. 392-398, out./dez. 2000.

ISO/DIS 5832-2: $1993^{7}$ e como grau 1, segundo a norma ASTM F 67-95 ${ }^{1}$. Já as das marcas Engimplan, Bucomax e Synthes foram classificadas como grau 1, conforme as duas normas citadas. Tal fato relaciona-se com o teste de flexão aplicado, uma vez que o titânio grau 2 apresenta uma resistência à flexão aproximadamente $30 \%$ maior do que a do titânio grau 1 , de acordo com as normas ISO/DIS 5832-2: $1993^{7}$ e ASTM F 67-95 ${ }^{1}$. Com relação aos parafusos, os resultados indicaram que os parafusos da W. Lorenz são elaborados com liga de titânio-6alumínio-4vanádio, de acordo com as normas ASTM F 1108-972 e ISO/DIS 5832-3: $1993^{8}$, conferindo resistência à flexão aproximadamente quatro vezes maior do que a do titânio co-

TABELA 1 - Análise da composição química das placas e parafusos.

\begin{tabular}{l|c|c|c|c}
\hline \hline Amostras & $\begin{array}{c}\text { Alumínio } \\
\left(\% \mathrm{~m} / \mathrm{m}^{*}\right)\end{array}$ & $\begin{array}{c}\text { Ferro } \\
\left(\% \mathrm{~m} / \mathrm{m}^{*}\right)\end{array}$ & $\begin{array}{c}\text { Vanádio } \\
\left(\% \mathrm{~m} / \mathrm{m}^{*}\right)\end{array}$ & Titânio \\
\hline $\begin{array}{l}\text { Placa } \\
\text { Engimplan }\end{array}$ & 0,02 & 0,04 & 0,03 & Balanço \\
\hline $\begin{array}{l}\text { Placa } \\
\text { Bucomax }\end{array}$ & 0,01 & 0,03 & 0,02 & Balanço \\
\hline $\begin{array}{l}\text { Placa } \\
\text { Synthes }\end{array}$ & $<0,008$ & 0,04 & 0,03 & Balanço \\
\hline $\begin{array}{l}\text { Placa W. } \\
\text { Lorenz }\end{array}$ & 0,03 & 0,17 & 0,03 & Balanço \\
\hline $\begin{array}{l}\text { Parafuso } \\
\text { Engimplan }\end{array}$ & 0,01 & 0,14 & 0,03 & Balanço \\
\hline $\begin{array}{l}\text { Parafuso } \\
\text { Bucomax }\end{array}$ & 0,03 & 0,13 & 0,03 & Balanço \\
\hline $\begin{array}{l}\text { Parafuso } \\
\text { Synthes }\end{array}$ & 0,02 & 0,02 & 0,03 & Balanço \\
\hline $\begin{array}{l}\text { Parafuso } \\
\text { W. Lorenz }\end{array}$ & 6,24 & 0,22 & 4,04 & Balanço \\
\hline \hline
\end{tabular}

O sinal "<" indica menor que o limite de detecção.

* Porcentagem massa/massa. mercialmente puro grau 1, encontrado nos parafusos das marcas Engimplan, Bucomax e Synthes ${ }^{1,7}$.

$\mathrm{O}$ uso combinado do titânio comercialmente puro e da liga titânio-6alumínio-4vanádio, o que certamente ocorre na marca comercial W. Lorenz, é contra-indicado pela probabilidade da ocorrência de corrosão galvânica, por se tratar de metais diferentes com potenciais eletroquímicos diferentes ${ }^{3,11}$. O titânio comercialmente puro é o que apresenta menos relatos associados a processos deletérios, que ocasionam o rompimento da homeostase tecidual local ou sistêmica. A tatuagem nos tecidos adjacentes é um relato comum, mas não há dados sobre a concentração que cause efeitos adversos ou mesmo se existe alguma ${ }^{5,10}$.

Não existe um material que possua ótimas características sob todos os aspectos necessários, havendo a necessidade de avaliação dos pontos favoráveis e contrários, de forma a equilibrar os efeitos adversos e os que tragam os beneficios espera$\operatorname{dos}^{12}$. Da mesma forma, pode-se dizer que cada marca comercial apresenta características próprias devido ao processo de fabricação, contemplando as placas e parafusos com padrão de qualidade variado.

Os dados obtidos mostraram que as medidas realizadas em placas e parafusos refletem um comportamento estatístico melhor, em termos de padronização de dimensões, das marcas comerciais importadas Synthes e W. Lorenz, quando comparadas às nacionais, Engimplan e Bucomax, visto que em nenhum dos dez locais onde as medidas foram realizadas (seis nas placas e quatro nos parafusos) as marcas nacionais foram mais regulares que as importadas. Dentre as marcas importadas, com relação às placas, a W. Lorenz apresentou melhor resultado e, entre as nacionais, a Bucomax com cinco medidas e a Engimplan com uma. Com relação aos parafusos, a marca importada Synthes apresentou menor variação, sendo que entre as nacionais a Engimplan apresentou vantagem em três das quatro medidas instituídas.

TABELA 2 - Valores da média final (mm) e do desvio-padrão das medidas realizadas nas placas.

\begin{tabular}{c|c|c|c|c|c|c}
\hline \hline \multirow{2}{*}{ Placa } & \multicolumn{6}{|c}{ Medida } \\
\cline { 2 - 7 } & I & II & III & IV & V & VI \\
\hline Engimplan & $1,598 \pm 0,180$ & $4,632 \pm 0,203$ & $3,590 \pm 0,286$ & $22,599 \pm 0,329$ & $2,461 \pm 0,263$ & $0,894 \pm 0,038$ \\
\hline Bucomax & $1,899 \pm 0,110$ & $4,361 \pm 0,093$ & $3,500 \pm 0,085$ & $22,517 \pm 0,158$ & $2,501 \pm 0,034$ & $0,915 \pm 0,053$ \\
\hline Synthes & $2,209 \pm 0,089$ & $4,820 \pm 0,026$ & $2,611 \pm 0,017$ & $*$ & $2,426 \pm 0,010$ & $0,852 \pm 0,020$ \\
\hline W. Lorenz & $1,984 \pm 0,010$ & $4,577 \pm 0,052$ & $4,262 \pm 0,040$ & $23,733 \pm 0,083$ & $2,126 \pm 0,007$ & $0,997 \pm 0,006$ \\
\hline \hline
\end{tabular}

* Neste caso as placas foram cortadas para obter-se as de quatro furos. 
TRIVELLATO, A. E.; MAZZONETTO, R.; PASSERI, L. A.; CONSANI, S. Estudo químico, macroscópico e da resistência à flexão de placas e parafusos de titânio usados na fixação interna rígida. Pesqui Odontol Bras, v. 14, n. 4, p. 392-398, out./dez. 2000.

TABELA 3 - Valores da média final (mm) e do desvio-padrão das medidas realizadas nos parafusos.

\begin{tabular}{c|c|c|c|c}
\hline \hline \multirow{2}{*}{ Parafuso } & \multicolumn{4}{|c}{ Medida } \\
\cline { 2 - 5 } & I & II & III & IV \\
\hline Engimplan & $2,995 \pm 0,032$ & $1,938 \pm 0,033$ & $1,984 \pm 0,036$ & $11,945 \pm 0,060$ \\
\hline Bucomax & $3,418 \pm 0,055$ & $1,841 \pm 0,091$ & $1,967 \pm 0,068$ & $11,960 \pm 0,090$ \\
\hline Synthes & $3,459 \pm 0,012$ & $1,727 \pm 0,013$ & $1,959 \pm 0,004$ & $11,975 \pm 0,014$ \\
\hline W. Lorenz & $2,931 \pm 0,012$ & $1,984 \pm 0,027$ & $1,963 \pm 0,019$ & $10,977 \pm 0,019$ \\
\hline \hline
\end{tabular}

TABELA 4 - Teste de Tukey aplicado aos resultados obtidos no teste de flexão das placas, ao nível de significância de $1 \%$.

\begin{tabular}{l|c|c|c}
\hline \hline \multicolumn{1}{c|}{ Marca } & $\mathrm{N}^{\circ}$ Rep. & Médias (kgf) & $1 \%$ \\
\hline W. Lorenz & 7 & 2,928572 & $\mathrm{~A}$ \\
\hline Synthes & 7 & 2,850000 & $\mathrm{~A}$ \\
\hline Engimplan & 7 & 1,535714 & $\mathrm{~B}$ \\
\hline Bucomax & 7 & 1,350000 & $\mathrm{~B}$ \\
\hline \hline
\end{tabular}

Médias seguidas por letras distintas diferem entre si ao nivel de significância indicado. Coeficiente de variação = $9,692 \%$.

O desenho e a composição química influenciam diretamente nos valores obtidos no ensaio de flexão, tanto para as placas como para os parafusos ${ }^{6}$. Segundo as normas da ASTM F $67-95^{1}$ e ISO/DIS 5832-2: $1993^{7}$, que descrevem os valores dos testes mecânicos para o titânio comercialmente puro, demostra-se um aumento de 30\%, no caso da resistência à flexão, quando o titânio grau 2 é comparado com o grau 1 . Tal fato pode explicar o melhor resultado no teste de flexão, apresentado pelas placas da marca comercial W. Lorenz, embora não diferencie da Synthes, estatisticamente. Dessa forma, pode-se referendar que os valores obtidos, neste estudo, estão diretamente relacionados com o desenho, com a padronização das dimensões e o material constituinte.

Com relação aos parafusos, os da marca comercial W. Lorenz são classificados como liga de titânio-6aluminio-4vanádio, o que lhes confere melhor resistência à flexão, com valores aproximadamente quatro vezes maiores do que o titânio comercialmente puro grau 1 , segundo norma da ASTM F $1108-97^{2}$ e da ISO/DIS 5832-3: $1993^{8}$. Outro ponto a salientar é a respeito da característica da rosca. Os parafusos das marcas Synthes e W. Lorenz apresentam rosca de passo menor, resultando em maior número delas, isto é 17 e 12 respectivamente, quando comparado aos da Engim-
TABELA 5 - Teste de Tukey aplicado aos resultados obtidos no teste de flexão dos parafusos, ao nível de significância de $1 \%$.

\begin{tabular}{l|c|c|c}
\hline \hline \multicolumn{1}{c|}{ Marca } & $\mathrm{N}^{\circ}$ Rep. & Médias (kgf) & $1 \%$ \\
\hline W. Lorenz & 7 & 17,714286 & $\mathrm{~A}$ \\
\hline Synthes & 7 & 14,857143 & $\mathrm{~B}$ \\
\hline Bucomax & 7 & 11,571429 & $\mathrm{C}$ \\
\hline Engimplan & 7 & 10,285714 & $\mathrm{C}$ \\
\hline
\end{tabular}

Médias seguidas por letras distintas diferem entre si ao nível de significância indicado. Coeficiente de variação = $10,055 \%$.

plan com 9 e da Bucomax com 8 roscas. Esses dados podem explicar o desempenho superior da marca W. Lorenz, estatisticamente significante em relação ao Synthes, a qual também demonstrou significância estatística em relação aos demais. Outro quesito, que poderia causar modificação na resistência à flexão, refere-se ao diâmetro interno do parafuso, que no presente estudo não foi avaliado.

Os resultados obtidos demonstraram uma melhor padronização na confecção de placas e parafusos das marcas importadas perante as nacionais, o que certamente refletirá num procedimento cirúrgico com menores intercorrências, devido ao material de fixação interna. Entretanto, a marca importada W. Lorenz apresentou parafuso confeccionado de liga titânio-6alumínio-4vanádio, o que lhe confere melhores propriedades mecânicas, mas não em termos de biocompatibilidade ${ }^{5}$.

\section{CONCLUSÕES}

Com base nos resultados obtidos, dentro das condições experimentais deste estudo, podemos concluir que:

1. por meio da espectrometria por dispersão de energia e posterior confirmação pela espectrometria de emissão atômica, pode-se afirmar que o parafuso da marca comercial W. Lorenz é con- 
TRIVELLATO, A. E.; MAZZONETTO, R.; PASSERI, L. A.; CONSANI, S. Estudo químico, macroscópico e da resistência à flexão de placas e parafusos de titânio usados na fixação interna rígida. Pesqui Odontol Bras, v. 14, n. 4, p. 392-398, out./dez. 2000.

feccionado de liga de titânio-6alumínio-4vanádio e os demais parafusos e placas são constituídos de titânio comercialmente puro;

2. as marcas comerciais nacionais demonstraram maiores alterações nas dimensões das placas e parafusos, sendo que a W. Lorenz demonstrou melhores resultados estatísticos na avaliação dimensional de placas, e no dos parafusos, a Synthes. Na comparação entre nacionais, a Bucomax sobressaiu com relação as placas e a Engimplan, com relação aos parafusos;

3. no teste de flexão das placas, os valores de resistência à flexão foram estatisticamente supe- riores para a Synthes e W. Lorenz, em comparação a Engimplan e Bucomax;

4. no teste de flexão dos parafusos, a W. Lorenz demonstrou resistência à flexão estatisticamente superior a Synthes que, por sua vez, foi estatisticamente melhor que Engimplan e Bucomax; entretanto, não se evidenciou diferença estatística entre as nacionais.

\section{AGRADECIMENTOS}

À professora Glaucia M. Bovi Ambrosano, pela orientação na análise estatística; à FAPESP pelo auxilio financeiro, a Engimplan pela doação do material avaliado e à UNICAMP.

TRIVELLATO, A. E.; MAZZONETTO, R.; PASSERI, L. A.; CONSANI, S. Chemical, macroscopical and bending resistance study of titanium plates and screws used in internal rigid fixation. Pesqui Odontol Bras, v. 14, n. 4, p. 392-398, out./dez. 2000.

The aim of this study was to compare four systems of titanium plates and screws (diameter of $2.0 \mathrm{~mm}$ ) used for internal rigid fixation. From them, two were made in Brazil (Engimplan and Bucomax), one in Switzerland (Synthes), and the other, in Germany (W. Lorenz). The following analyses were done: chemical analysis using Energy Dispersive Spectroscopy (EDS) and Atomic Emission Spectroscopy (AES), measurement of dimensions and bending resistance test. The obtained results allow to conclude that both Brazilian systems showed inferior behavior regarding dimensional standards. The bending assay showed that the Brazilian systems are similar to each other. However, the W. Lorenz screws are made of titanium-6aluminum-4vanadium alloy, which can be the reason for their better performance in the bending assay, when compared with that of the other three systems. The remaining plates and screws are made of commercially pure titanium as confirmed by EDS and AES.

UNITERMS: Plate; Screw; Chemical analysis; Bending resistance.

\section{REFERÊNCIAS BIBLIOGRÁFICAS}

1. AMERICAN SOCIETY FOR TESTING AND MATERIALS (ASTM): Standard specification for unalloyed titanium for surgical implant applications. Designation: F 67-95. In: Annual book of ASTM standards. Medical devices and services, v. 13.01, p. 1-3, 1997.

2. AMERICAN SOCIETY FOR TESTING AND MATERIALS (ASTM): Standard specification for titanium6aluminum-4vanadium alloy castings for surgical implant (UNS R56406). Designation: F 1108-97. In: Annual book of ASTM standards. Medical devices and services, v. 13.01, p. 380-382, 1997.

3. BLOCK, M. S.; KENT J. N. Endosseous implants for maxillofacial reconstruction. Philadelphia: Saunders, 1993. p. 56-74.

4. ELLIS, E. Rigid skeletal fixation of fractures. J Oral Maxillofac Surg, v. 51, n. 2, p. 163-173, Feb. 1993.

5. HAUG, R. H. Retention of asymptomatic bone plates used for orthognathic surgery and facial fractures. J Oral Maxillofac Surg, v. 54, n. 6, p. 611-617, June 1996.

6. HEGTVEDT, A. K.; MICHAELS, G. C.; BEALS, D. W. Comparison of the resistance of miniplates and microplates to various in vitro forces. J Oral Maxillofac Surg, v. 52, n. 2, p. 251-257, Feb. 1994.
7. INTERNATIONAL ORGANIZATION FOR STANDARDIZATION/DRAFT INTERNATIONAL STANDARDS (ISO/DIS) Implants for surgery - metallic materials - part 2: unalloyed titanium. Reference number ISO/DIS 5832-2, 1993. p. 1-3.

8. INTERNATIONAL ORGANIZATION FOR STANDARDIZATION/DRAFT INTERNATIONAL STANDARDS (ISO/DIS) Implants for surgery - metallic materials - part 3: wrought titanium-6aluminium-4vanadium alloy. Reference number ISO/DIS 5832-3, 1993. p. 1-4.

9. JONES, J. K.; VAN SICKELS, J. E. Rigid fixation: a review of concepts and treatment of fractures. Oral Surg Oral Med Oral Pathol, v. 65, n. 1, p. 13-18, Jan. 1988.

10. KIM, Y. K.; YEO, H. H.; LIM, S. C. Tissue response to titanium plates: a transmitted electron microscopic study. J Oral Maxillofac Surg, v. 55, n. 3, p. 322-326, Mar. 1997.

11. SILVA, R. A.; BARBOSA, M. A.; JENKINS, G. M.; WEBER, $\mathrm{H}$. Electrochemistry of galvanic couples between carbon and common metallic biomaterials in the presence of crevices. Biomaterials, v. 11 , n. 3, p. 336-340, Mar. 1990.

12. YAREMCHUK, M. J.; GRUSS, J. S.; MANSON, P. N. Rigid fixation of the craniomaxillofacial skeleton. Boston : Butterworth-Heinemann, 1992. p. 28-56.

Recebido para publicação em $27 / 04 / 00$ Enviado para reformulação em 19/07/00 Aceito para publicação em 07/08/00 